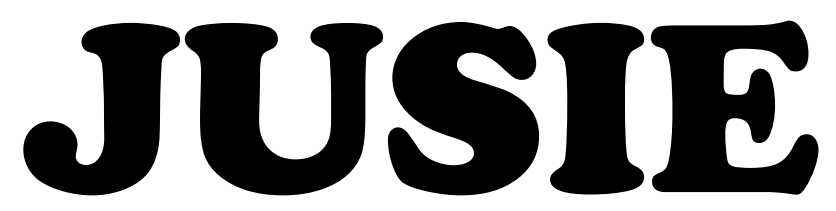

(Jurnal Sosial dan Ilmu Ekonomi)

Volume IV, Nomor 02, November 2019 - April 2020

Prosedur Pencairan dan Penerimaan Alokasi Dana Desa (ADD) untuk Pembangunan Nagari Tabek Panjang Kecamatan Baso Kabupaten Agam

Penulis $\quad$ : Sabri, Eka Febrianti, Asnah dan Nasfi

Sumber $\quad$ : Jurnal Sosial dan Ilmu Ekonomi, Volume IV, Nomor 02, November 2019 April 2020

Diterbitkan oleh: Jurusan PIPS FKIP UMMY Solok 


\title{
Prosedur Pencairan dan Penerimaan Alokasi Dana Desa (ADD) untuk Pembangunan Nagari Tabek Panjang Kecamatan Baso Kabupaten Agam
}

\author{
Sabri $^{1}$, Eka Febrianti ${ }^{2}$, Asnah ${ }^{3}$, Nasfi ${ }^{4}$ \\ 1,2,3 Sekolah Tinggi Ilmu Ekonomi Haji Agus Salim Bukittinggi \\ ${ }^{4}$ STES Manna Wa Salwa, Padang Panjang \\ Email: sabribgk@gmail.com \\ Email: ekafebriantiardi78@gmail.com \\ Email: asnahanas81@gmail.com \\ Email: nasfi.anwar@gmail.com
}

\begin{abstract}
The purpose of this study was to determine the procedure for disbursing village fund allocations and how to receive village fund allocation (ADD) in the 2018 fiscal year at Nagari Tabek Panjang, Baso District. This research is located in Nagari Tabek Panjang, Baso District, Agam Regency, West Sumatra Province. The type of data used is qualitative data. Data collection was carried out by means of interviews and documentation by determining the parties who became the resource persons. The results showed that the Village Fund Allocation (ADD) disbursement procedure was carried out in stages namely stages I, II, III. For disbursement in the first phase after the Nagari Regulation on ABPNag 2018 was approved by the Agam Regency Nagari Community Empowerment Agency (DPMN) verification team, and for the second stage disbursement must report accountability to the Agam Regency DPMN. In the ADD Acceptance Process, the Nagari RPJM was compiled, the Nagari RKP Compilation and Determination, and the Nagari Expenditure Budget (APBNAg) Long Term Budgeting Budget Compilation 2018
\end{abstract}

Keywords: Disbursement Procedure, Acceptance Procedure, Village Fund Allocation

\begin{abstract}
ABSTRAK
Tujuan dari penelitian ini untuk mengetahui prosedur pencairan alokasi dana desa dan bagaimana cara penerimaan alokasi dana desa (ADD) tahun anggaran 2018 pada Nagari Tabek Panjang, Kecamatan Baso. Penelitian ini berlokasi di Nagari Tabek Panjang, Kecamatan Baso, Kabupaten Agam, Provinsi Sumatera Barat. Jenis data yang digunakan adalah data kualitatif. Pengumpulan data dilakukan dengan cara Wawancara dan dokumentasi dengan menentukan pihak - pihak yang menjadi narasumber. Hasil penelitian menunjukkan bahwa prosedur pencairan Alokasi Dana Desa (ADD) dilakukan secara bertahap yaitu tahap I, II, III. Untuk pencairan di tahap pertama setelah Peraturan Nagari tentang ABPNag Tahun 2018 disetujui oleh tim verifikasi Dinas Pemerdayaan Masyarakat Nagari (DPMN) Kabupaten Agam, dan untuk pencairan ditahap kedua harus melaporkan pertanggungjawaban kepada DPMN Kabupaten Agam. Dalam Proses Penerimaan ADD dilakukan penyusunan RPJM Nagari, Penyusunan dan Penetapan RKP Nagari, dan Penyusunan Anggaran Pendapatan Belanja Nagari (APBNAg) Tabek Panjang Tahun Anggaran 2018
\end{abstract}

Kata Kunci : Prosedur Pencairan, Prosedur Penerimaan, Alokasi Dana Desa 


\section{PENDAHULUAN}

Penyelenggaraan urusan Pemerintahan Desa yang menjadi kewenangan Desa di danai dari Anggaran Pendapatan dan Belanja Desa (APBDesa). APBDesa terdiri atas bagian Pendapatan Desa, Belanja Desa dan Pembiayaan. Anggaran merupakan suatu rencana yang telah disusun secara sistematis yang meliputi seluruh kegiatan yang dinyatakan dalam unit kesatuan dan berlaku untuk jangka waktu tertentu. Anggaran juga disebut Rencana Keuangan sehingga dapat diukur pencapaian efesiensi dan efektivitas dari kejadian yang dilakukan. Anggaran keuangan yang diberikan Pemerintah kepada Desa berasal dari Bagi Hasil Pajak Daerah, Dana Perimbangan keuangan pusat dan daerah yang diterima oleh Kabupaten disebut alokasi dana desa. Alokasi Dana Desa (ADD) merupakan kewajiban Pemerintah Kabupaten atau kota untuk mengalokasikan Anggaran Desa yang dikembalikan dari Dana Bagi Hasil (DBH) dan Dana Alokasi Umum ( DAU) yang merupakan dana perimbangan. Alokasi dana desa harus dicatat di dalam anggaran pendapatan dan belanja desa melalui proses penganggaran yang sesuai dengan mekanisme yang berlaku.

Dana ADD dicairkan dalam dua tahap yakni pada tahap pertama sebesar $60 \%$ dan tahap kedua sebesar 40\% sesuai kebutuhan pada rincian APBDes. Adapun mekanisme pencairan ADD tahap pertama adalah setiap desa harus menyusun Rencana Pembangunan Jangka Menengah Desa, Rencana Kerja Pemerintah Desa, dan anggaran Pendapatan dan Belanja. Untuk pencairan dana yang $40 \%$ Pemerintah desa cukup menyampaikan Laporan Pelaksanaan Pertanggungjawaban Pelaksanaan ADD tahap pertama, melengkapi RPD untuk yang 40\% dan dilengkapi kuitansi sejumlah 40\% yang diajukan dengan materai 6.000. Semua dana ADD digunakan untuk Penyelenggaraan pemerintah Desa dalam rangka Pelayanan Puplik dalam hal Administrasi dan pembangunan Sarana dan Prasarana untuk kepentingan Desa.

ADD diterima dalam Rekening Kas Desa (RKD) setiap Tahun. Namun dalam hal pelaksanaan prosedur pencairan dan penerimaan ADD masih belum sesuai dengan ketentuan atau harapan dimana prosedur pencairan ADD pada Nagari Tabek Panjang masih banyak ditemukan kelemahan dan kekurangan, sehingga penyerapan ADD di Nagari Tabek Panjang tersebut terhambat begitu juga yang ditemui beberapa daerah banyak yang terlambat. Pencairan hal lain yang menjadi keluhan bagi Nagari Tabek Panjang yaitu tambahan persyaratan penyaluran dana dari RKUD Ke Rekening Kas Desa (RKD) Seperti dokumen RPJMDes dan RKPDes yang terkesan seperti disengaja untuk mempersulit kepentingan desa. Sehingga pelaksanaan pembangunan untuk kemajuan Nagari juga terganggu. Mengingat pentingnya Anggaran dan Pengelolaan keuangan Desa tersebut dan berdasarkan latar belakang uraian diatas maka peneliti tertarik untuk melakukan penelitian yang berjudul "Prosedur Pencairan dan Penerimaan Alokasi Dana Desa (ADD) Untuk Pembangunan Nagari Tabek Panjang Kecamatan Baso.

\section{METODE PENELITIAN}

Metode peneltian yang digunakan meliputi beberapa bagian :

\section{Sumber Data}

Sumber-sumber data yang dibutuhkan dalam hubungannya dengan prngumpilan data dikelompokkan menjadi :

a. Sumber Data Primer

Data primer adalah data yang diperoleh secara langsung dari sumber asli, data diperoleh berupa hasil wawancara. Data primer secara khusus diperoleh dengan cara wawancara langsung dengan pihak yang bersangkutan.

b. Sumber Data Sekunder

Diperoleh dari buku-buku literatur, jurnal ilmiah, skripsi, dan sebagaimana yang memuat informasi-informasi yang diperlukan dalam penyusunan Tugas Akhir. 


\section{Teknik Pengumpulan Data}

Untuk mendapatkan informasi yang lengkap dan jelas, penelitian dilakukan dengan beberapa metode yaitu :

a. Metode Observasi

Observasi adalah melakkan pengamatan secara langsung dan pencatatan tentang keadaan atau fenomena yang dijumpai.

b. Metode Wawancara

Dengan cara tanya jawab langsung dengan pihak-pihak yang terkait dengan penelitian yang dilakukan

c. Metode Studi Kepustakaan

Metode studi kepustakaan dilakukan untuk menunjang metode observasi dan wawancara yang telah dilakuka. Pengumpulan informasi yang dibutuhkan dengan mencari referensi-referensi yang berhubungan dengan penelitian yang dilakukan, referensi dapat diperoleh dari buku-buku atau internet.

\section{Teknik Analisa Data}

\section{a. Analisis Data Kuantitatif}

Ada beberapa tipe analisis data kuantitatif salah satu yang paling populer adalah analisis regresi. Analisis regresi mengukur hubungan antara variabel denpenden dengan variabel indenpenden. Ringkasnya, analisis regresi menunjukkan perubahan nilai variabel denpenden ketika variabel indenpenden berada pada nilai yang tetap.

\section{b. Analisis Data Kualitatif}

Analisis data Kualitatif dilakukan dengan cara coding. Proses coding melibatkan penentuan konsep atau varibel yang mendahului. Coding memfasilitasi peneliti untuk membuat kesimpulan yang valid dan sistematis, Secara ringkas, koding merupakan proses kategori data kualitatif sehingga bisa dengan mudah diukur atau dipahami.

\section{HASIL PENELITIAN DAN PEMBAHASAN}

\section{A. Kondisi Nagari Tabek Panjang}

\section{Kondisi Geografis Nagari Tabek Panjang}

Berdasarkan ketentuan Administratif Nagari Tabek Panjang terdiri dari 4 Jorong, yaitu: Jorong Baso, Jorong Tabek Panjang, Jorong Sungai Janiah dan Jorong Sungai Cubadak. Dilihat dari potensi masing-masing Jorong Nagari Tabek Panjang bepeluang untuk dikembangkan sebagai daerah transit, pariwisata, perdagangan dan Pertanian. Hal ini dikarenakan posisi strategisnya sebagai kawasan Hitterland Agropolitan Kab.Agam dan Lintas segi tiga Payakumbuh, Batusangkar dan Bukittinggi. Topografi adalah gambaran tentang tingkat kemiringan dan ketinggian tanah dari permukaan laut. Kondisi kemiringan tanah merupakan salah satu faktor yang sangat mempengaruhi kesesuaian lahan untuk syarat tumbuh suatu tanaman. Karena dengan kemiringan tanah yang sedang akan sangat mempengaruhi kontuinitas kesuburan tanah. Seperti terlihat dalam tabel berikut ini:

\section{Tabel 1. Luas dan Tingkat Kemiringan Tanah}

\begin{tabular}{|c|l|c|c|}
\hline No & \multicolumn{1}{|c|}{ Topografi } & Kemiringan & Luas (Ha) \\
\hline 1 & Agak Landai & $0-15 \%$ & 1552 \\
\hline 2 & Agak Curam & $16-25 \%$ & 200 \\
\hline 3 & Curam & $26-45 \%$ & 50 \\
\hline 4 & Sangat Curam & $>45 \%$ & 17 \\
\hline & Total & & 1919 \\
\hline
\end{tabular}

Sumber : Profil Nagari Tahun 2018

Dari data tersebut diatas menggambarkan bahwa tingkat kemiringan agak landai $0 \%-25 \%$ dengan kategori kelompok tanah datar dan bergelombang yang dinilai cocok dan sesuai untuk lahan budidaya pertanian tanaman pangan dan hortikultura serta lahan perkebunan rakyat mempunyai luas 1452 Ha atau 75,6\% dari luas Nagari. Sementara kondisi lahan dengan tingkat kemiringan 26\% - 60\% dengan kategori kondisi tanah berbukit dan bergunung yang dinilai cocok dan sesuai untuk lahan beberapa jenis 
tanaman perkebunan dan tanaman hutan mempunyai luas 467 Ha atau $24.33 \%$ dari luas daerah.

\section{Gambaran Umum Demografis}

Secara teoritis disebutkan bahwa jumlah penduduk yang besar merupakan salah satu modal dasar pembangunan. Hal ini dimaksudkan apabila jumlah penduduk yang besar tersebut dapat diberdayakan sesuai kodrat, keahlian dan bidang kerjanya masingmasing. Sebaliknya apabila jumlah penduduk yang besar tadi tidak dapat diberdayakan dan dikendalikan secara bijak dan terencana bahkan akan menjadi beban pembangunan. Berdasarkan data terakhir dari Laporan Pengiriman Mutasi Penduduk Tahun 2018, jumlah penduduk Nagari Tabek Panjang sebesar 9.623 jiwa. Untuk lebih jelasnya dapat dilihat pada tabel sebagai berikut :

Tabel 2. Jumlah dan Pertumbuhan Penduduk Nagari Tabek Panjang

\begin{tabular}{|l|c|c|c|c|c|}
\hline \multirow{2}{*}{\multicolumn{1}{c|}{ Jorong }} & \multicolumn{5}{c|}{ Jumlah Penduduk } \\
\cline { 2 - 6 } & $\mathbf{2 0 1 4}$ & $\mathbf{2 0 1 5}$ & $\mathbf{2 0 1 6}$ & $\mathbf{2 0 1 7}$ & $\mathbf{2 0 1 8}$ \\
\hline Baso & 3.554 & 3.550 & 3.561 & 3.562 & 3.554 \\
\hline Tabek Panjang & 2.260 & 2.236 & 2.199 & 2.149 & 2.132 \\
\hline Sungai Janiah & 1.094 & 1.082 & 1.052 & 1.024 & 1.041 \\
\hline Sungai Cubadak & 2.857 & 2.824 & 2.837 & 2.868 & 2.896 \\
\hline
\end{tabular}

Sumber : Data Base Nagari Tabek Panjang Tahun 2018

Dari data di atas menggambarkan jumlah penduduk yang paling tertinggi pada tahun 2014 sebesar 9.765 jiwa, dan jumlah penduduk yang paling terendah terjadi pada tahun 2017 sebesar 9.603 jiwa.

Tabel 3. Jumlah Penduduk Berdasarkan Jenis Kelamin

\begin{tabular}{|c|l|c|c|c|}
\hline No & \multicolumn{1}{|c|}{ Jorong } & Laki - laki & Perempuan & Jumlah \\
\hline 1 & Baso & 1.749 & 1.805 & 3.554 \\
\hline 2 & Tabek Panjang & 1.067 & 1.065 & 2.132 \\
\hline 3 & Sungai Janiah & 516 & 525 & 1.041 \\
\hline 4 & Sungai Cubadak & 1.453 & 1.443 & 2.896 \\
\hline & Total & 4.785 & 4.838 & 9.623 \\
\hline
\end{tabular}

Sumber : Data Kependudukan Nagari Tabek Panjang 2018

Dari data di atas menggambarkan jumlah penduduk tertinggi pada Jorong Baso yaitu Laki - laki sebanyak 1.749 jiwa, dan Perempuan sebanyak 1805 jiwa dengan jumlah 3.554 jiwa.

Tabel 4. Jumlah Penduduk Berdasarkan Umur

\begin{tabular}{|c|c|c|}
\hline No & Umur & Jumlah (Orang) \\
\hline 1 & $0<12$ Bulan & 1.078 \\
\hline 2 & $1-<10$ Tahun & 1.123 \\
\hline 3 & $10-<20$ Tahun & 1.166 \\
\hline 4 & $20-<30$ Tahun & 1.160 \\
\hline 5 & $30-<40$ Tahun & 1.027 \\
\hline 6 & $40-<50$ Tahun & 1.981 \\
\hline 7 & $50-<60$ Tahun & 1.109 \\
\hline 8 & $60-<70$ Tahun & 677 \\
\hline 9 & $>70$ Tahun & 302 \\
\hline & Jumlah & 9.623 \\
\hline
\end{tabular}

Sumber : Data Kependudukan Nagari Tabek Panjang 2018

Dari tabel di atas menggambarkan jumlah penduduk tertinggi adalah berumur $40-<$ 50 Tahun yaitu berjumlah 1.981 jiwa, sedangkan yang terendah adalah berumur $>70$ Tahun yaitu berjumlah 302 jiwa. 
Tabel 5. Jumlah Sarana Pendidikan

\begin{tabular}{|c|l|c|c|c|c|c|}
\hline \multirow{2}{*}{ No } & \multicolumn{1}{|c|}{ Jorong } & \multicolumn{5}{|c|}{ Jenis Sarana Pendidikan } \\
\cline { 3 - 7 } & & TK & SD & SMP & SMA & PT \\
\hline 1 & Sungai Janiah & 1 & 1 & - & - & - \\
\hline 2 & Tabek Panjang & 1 & 2 & - & - & - \\
\hline 3 & Baso & 1 & 1 & 1 & 1 & - \\
\hline 4 & Sungai Cubadak & 2 & 2 & 2 & 1 & 1 \\
\hline & Jumlah & $\mathbf{5}$ & $\mathbf{6}$ & $\mathbf{2}$ & $\mathbf{2}$ & $\mathbf{1}$ \\
\hline
\end{tabular}

Sumber Data Nagari Tabek Panjang 2018

Dari data di atas menggambarkan Sarana Pendidikan terbanyak berada pada Jorong Sungai Cubadak, dan yang paling sedikit berada pada Jorong Sungai Janiah.

Tabel 6. Jumlah Sarana Kesehatan

\begin{tabular}{|c|l|c|c|c|c|}
\hline \multirow{2}{*}{ No } & \multicolumn{1}{|c|}{ Jorong } & \multicolumn{4}{|c|}{ Jenis Sarana Kesehatan } \\
\cline { 3 - 6 } & & Pustu & Polindes & Bidan Desa & Posyandu \\
\hline 1 & Sungai Janiah & 1 & - & 1 & 2 \\
\hline 2 & Tabek Panjang & - & - & 1 & 4 \\
\hline 3 & Baso & - & 1 & 2 & 6 \\
\hline 4 & Sungai Cubadak & 1 & 1 & 1 & 5 \\
\hline & Jumlah & $\mathbf{1}$ & $\mathbf{2}$ & $\mathbf{5}$ & $\mathbf{1 7}$ \\
\hline
\end{tabular}

Sumber Data Nagari Tabek Panjang 2018

Dari data di atas menggambarkan Jumlah Sarana Kesehatan terbanyak berada pada jorong Baso yaitu berjumlah 9 Sarana Kesehatan, dan yang paling sedikit berada pada jorong Sungai Janiah yaitu berjumlah empat Sarana Kesehatan.

Tabel 7. Jumlah Sarana Umum

\begin{tabular}{|c|l|c|c|c|c|c|}
\hline \multirow{2}{*}{ No } & \multicolumn{1}{|c|}{ Jorong } & \multicolumn{5}{|c|}{ Jenis Fasilitas Umum } \\
\cline { 3 - 7 } & & Msj & Msl & Posy & Ronda & Lapangan \\
\hline 1 & Sungai Janiah & 1 & 5 & 2 & 2 & - \\
\hline 2 & Tabek Panjang & 2 & 4 & 4 & 4 & 1 \\
\hline 3 & Baso & 1 & 6 & 6 & 4 & - \\
\hline 4 & Sungai Cubadak & 1 & 1 & 5 & 3 & - \\
\hline
\end{tabular}

Sumber Data Nagari Tabek Panjang 2018

Dari data di atas menggambarkan Jumlah Sarana Umumterbanyak di Nagari Tabek Panjang berada pada jorong Baso yaitu sebanyak 17 Sarana Umum.

Tabel 8. Jumlah Aparatur Pemerintahan Nagari

\begin{tabular}{|c|l|c|c|c|c|c|}
\hline \multirow{2}{*}{ No } & \multirow{2}{*}{ Jorong } & \multicolumn{5}{|c|}{ Aparatur Pemerintahan Nagari } \\
\cline { 3 - 7 } & & Perangkat & Wali Jorong & Staf & BAMUS & LeNagari \\
\hline 1 & Sungai Janiah & 1 & 1 & 1 & 2 & 29 \\
\hline 2 & Tabek Panjang & 2 & 1 & - & 2 & 36 \\
\hline 3 & Baso & 4 & 1 & - & 3 & 39 \\
\hline 4 & Sungai Cubadak & - & 1 & - & 2 & 35 \\
\hline & Jumlah & 7 & 4 & 1 & 9 & 139 \\
\hline
\end{tabular}

Sumber Data Nagari Tabek Panjang 2018

Berdasarkan Peraturan Bupati Agam Nomor 12 Tahun 2017 tentang Pembentukan Nagari Persiapan Sungai Cubadak yang ditetapkan tanggal 16 Maret 2017, untuk itu diangkat Penjabat Walinagari Persiapan Sungai Cubadak sesuai dengan Keputusan Bupati Agam Nomor 540 Tahun 2017 dan diangkat Perangkat Nagari Persiapan Sungai Cubadak Periode 2018 sampai Terbentuknya Nagari Defenitif sesuai Surat Keputusan Pejabat Walinagari Persiapan Sungai Cubadak Nomor 02 Tahun 2018 sebanyak 5 (lima) orang yang terdiri dari Sekretaris Nagari, Kasi Pemerintahan, Kasi Pelayanan dan Kesejahteraan, Kaur Umum dan Perencanaan, Kaur Keuangan. 


\section{B. Prosedur Pencairan Alokasi Dana Desa (ADD) Tahun Anggaran 2018 pada Nagari Tabek Panjang}

1. Prosedur Pencairan Alokasi Dana Desa (ADD) Tahun Anggaran 2018 pada Nagari Tabek Panjang

a. Proses Pencairan Alokasi Dana Desa (ADD)

Pada tahap ini dilakukan wawancara dengan Sekretaris Nagari Tabek Panjang pada Rabu 07 Agustus 2019, diperoleh informasi bahwa proses pencairan ADD di Nagari Tabek Panjang terbagi atas 2 (dua) tahap yaitu :

1) Penghasilan tetap Wali Nagari dan perangkat Nagari serta tunjangan Bamus

a) Triwulan pertama Bulan Januari sebesar $25 \%$ dari Pagu Anggaran gaji keseluruhan perangkat nagari dan Bamus

b) Triwulan kedua paling cepat bulan Maret sebesar 25\% dari Pagu Anggaran gaji keseluruhan perangkat nagari dan Bamus

c) Triwulan ketiga paling cepat bulan Juni sebesar $25 \%$ dari Pagu Anggaran gaji keseluruhan perangkat Nagari dan Bamus

d) Triwulan ke empat pada bulan September $25 \%$ dari Pagu Anggaran gaji keseluruhan perangkat Nagari dan Bamus.

2) Pencairan Alokasi Dana Desa (ADD) selain dari penghasilan tetap perangkat Nagari serta tunjangan Bamus, dibagi tiga tahap :

a) Paling cepat bulan Februari sebesar $40 \%$.

b) Paling cepat bulan Juni sebesar $40 \%$.

c) Paling cepat bulan Oktober sebesar $20 \%$.

b. Tata Cara Pelaksanaan Pencairan Alokasi Dana Desa (ADD).

1) Tahap I berupa :

a) Peraturan Nagari tentang APB Nagari

b) Surat Permintaan Pencairan dari Pemerintah Nagari

c) Laporan Realisasi pelaksanaan ABP Nagari tahun sebelumnya yang telah direkonsiliasi di tingkat Kecamatan

d) Rekomendasi Camat untuk penyaluran dana ADD

Setelah Peraturan Nagari tentang APBNag Tahun 2018 disetujui tim verifikasi

oleh Dinas Pemerdayaan Masyarakat Nagari (DPMN) Kabupaten Agam maka pencairan tahap pertama ADD telah dapat direalisasikan.

2) Tahap II berupa :

a) Surat Permintaan Pencairan dari Pemerintah Nagari

b) Laporan Realisasi pelaksanaan APBNag sampai dengan bulan sebelum permintaan penyaluran yang telah direkonsiliasi di tingkat Kecamatan

c) Laporan Realisasi Penggunaan ADD yang telah disalurkan sekurang - kurangnya $80 \%$ dan telah direkonsiliasi di tingkat Kecamatan

d) Rekomendasi Camat untuk penyaluran dana ADD Tahap II.

Setelah dilakukan kegiatan di tahap pertama untuk pengajuan pencairan tahap kedua harus melaporkan pertanggungjawaban kepada Dinas Pemerdayaan Masyarakat Nagari (DPMN) Kabupaten Agam.

3) Tahap III berupa :

a) Surat Permintaan Pencairan dari Pemerintah Nagari

b) Laporan Realisasi pelaksanaan APBNAg samapi dengan bulan sebelum yang telah direkonsiliasi di tingkat Kecamatan

c) Laporan Realisasi Penggunaan ADD yang telah disalurkan sekurang - kurangnya $80 \%$ dan telah direkonsiliasi di tingkat Kecamatan

d) Rekomendasi Camat untuk penyaluran dana ADD tahap III.

Setelah dilakukan kegiatan di tahap kedua untuk pengajuan pencairan di tahap ketiga harus melaporkan pertanggungjawaban kepada Dinas Pemerdayaan Masyarakat Nagari (DPMN) Kabupaten Agam. Untuk lebih rincina akan ditampilkan Flowchart prosedur pencairan Alokasi Dana Desa (ADD) Tahun Anggaran 2018 pada Nagari Tabek Panjang berikut ini 


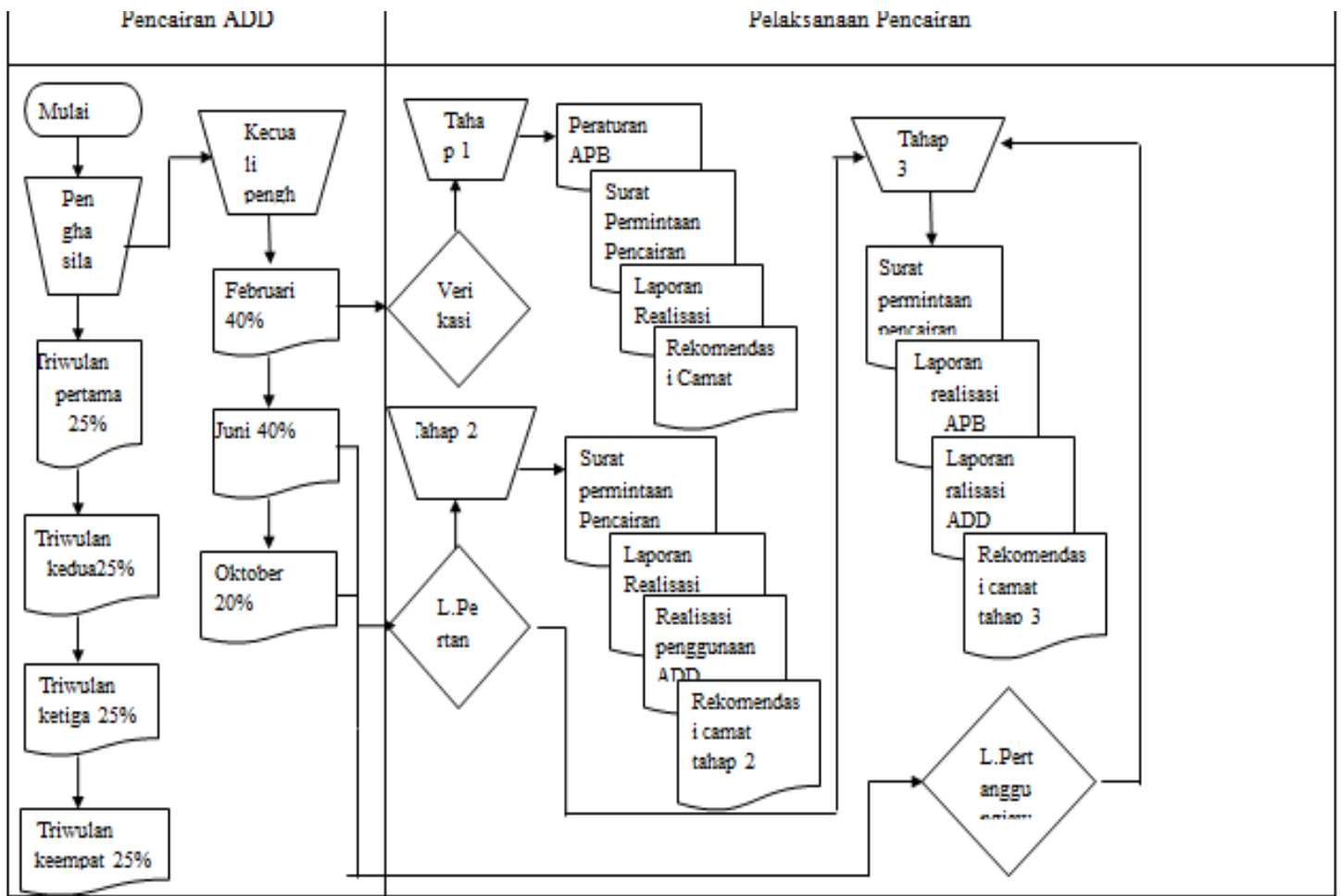

Gambar 1. Flowchart Prosedur Pencairan ADD

\section{Prosedur Penerimaan Alokasi Dana Desa (ADD) tahun Anggaran 2018 pada Nagari Tabek Panjang Kecamatan Baso}

1. Penyusunan Rencana Pembangunan Jangka Menengah (RPJMDes)

Dalam penyusunan RPJMDes diatur dalam persetujuan Bupati No. 542017 tentang petunjuk teknis Penyusunan Rencana Pembangunan Jangka Menengah (RPJM) disusun untuk jangka waktu 6 Tahun Nagari Tabek Panjang Tahun 2014 - 2020). Adapun proses penetapan RPJMDes berlangsung paling lama 3 Bulan terhitung sejak pelantikan. RPJMDes memuat visi misi Wali Nagari dan apa yang akan dikerjakan selama memimpin nagarinya. Dalam RPJMDes terdapat arah kebijakan pembangunan desa, rencana kegiatan yang meliputi penyelenggaraan pemerintahan Nagari, pelaksanaan pembangunan Nagari, pembinaan kemasyarakatan Nagari dan pemberdayaan masyarakat yang akan dilakukan pemerintah Nagari. Setidaknya ada tujuh langkah yang harus dipenuhi dalam menyusun RPJMDes yaitu :

a. Harus ditetapkan dalam surat keputusan Nagari dari Pembina antara lain Wali Nagari, Sekretaris Nagari, Ketua LPMD, anggotanya LPMD, KPMD, dan Masyarakat perwakilan kelompok masyarakat yang lain.

b. Wali Nagari membentuk tim penyusun RPJMDes yang mana jumlah tim tersebut minimal 7 (tujuh) orang dan maksimal 11 (sebelas) orang dan harus mengikutsertakan perempuan $30 \%$.

c. Melakukan penyelarasan dengan arah kebijakan Kabupaten/Kota, Sebelum menyusun isi RPJMDes, seluruh tim harus lebih dahulu memahami arah kebijakan pemerintah kabupaten sehingga tidak terjadi ketidaksesuaian.

d. Kajian kondisi Nagari antara lain harus melakukan penyelarasan data Nagari, penggalian aspirasi melalui musyawarah ditingkat Nagari dan menyusun pelaporan atas proses pembacaan kondisi ini.

e. Penyusunan Rencana Pembangunan Nagari melalui Musyawarah Nagari (MUSNA).

f. Laporan hasil kajian kondisi Nagari.

g. Prioritas rencana kegiatan Nagari dalam jangka waktu 6 (Enam) Tahun.

$\mathrm{h}$. Sumber pembiayaan rencana kegiatan pembangunan nagari.

i. Rencana pelaksanaan kegiatan nagari yang akan dilaksanakan oleh perangkat nagari, unsur masyarakat, dan kerjasama antar nagari. 
j. Penyusunan rencana pembangunan nagari melalui musyawarah perencanaan pembangunan nagari.

k. Penyempurnaan dan penetapan rancangan RPJMDes.

\section{Rencana Kerja Pemerintah (RKP) Nagari Tabek Panjang Tahun 2018}

RKP Nagari mulai disusun oleh pemerintah Nagari pada bulan Juli tahun berjalan. RKP Nagari ditetapkan dengan peraturan Nagari paling lambat akhir bulan September tahun berjalan. RKP Nagari menjadi dasar penetapan APB Nagari. Wali Nagari menyusun RKP Nagari dengan mengikutsertakan Masyarakat Nagari. Sesuai peraturan Menteri Dalam Negeri (Permendagri) Nomor 114 Tahun 2014 tentang pedoman Pembangunan Nagari, tahapan penyusunan Rencana Kerja Pemerintah (RKP) Nagari meliputi :

a. Penyusunan Perencanaan Pembangunan Nagari melalui Musyawarah Nagari (MUSNA)

Badan Permusyawaratan Nagari menyelenggarakan musyawarah nagari dalam rangka penyusunan rencana pembangunan nagari yang menjadi pedoman bagi pemerintah nagari menyusun rancangan RKP Nagari dan daftar usulan RKP Nagari. Badan Permusyawaratan Nagari menyelenggarakan MUSNA paling lambat bulan Juni tahun berjalan. Musyawarah Nagari (MUSNA) melaksanakan kegiatan sebagai berikut :

1) Mencermati ulang dokumen RPJMDes

2) Menyepakati hasil pencermatan ulang dokumen RPJMDes

3) Membentuk tim verifikasi sesuai dengan jenis kegiatan dan keahlian yang dibutuhkan.

Tim verifikasi dapat berasal dari warga masyarakat Nagari dan satuan kerja perangkat Daerah Kabupaten/Kota. Hasil kesepakatan dituangkan dalam berita acara yang menjadi pedoman Wali Nagari dalam menyusun RKP Nagari.

b. Pembentukan Tim Penyusun RKP Nagari

Wali Nagari membentuk tim penyusun RKP Nagari, yang terdiri dari:

1) Wali Nagari selaku pembina

2) Sekretaris Nagari selaku ketua

3) Ketua lembaga pemberdayaan masyarakat sebagai sekretaris

4) Anggota yang meliputi perangkat nagari, lembaga pemberdayaan dan masyarakat, kader pemberdayaan masyarakat nagari, dan unsur masyarakat.

Tim penyusun RKP Nagari melaksanakan kegiatan sebagai berikut:

1) Pencermatan Pagu Indikatif Nagari dan penyelarasan program kegiatan masuk ke nagari

2) Percermatan ulang dokumen RPJMDes

3) Penyusunan rancangan RKP Nagari

4) Penyusunan rancangan daftar usulan RKP Nagari

c. Percermatan Pagu Indikatif Nagari dan penyelarasan kegiatan masuk ke Nagari

Tim penyusun RKP Nagari melakukan percermatan Pagu Indikatif Nagari meliputi:

1) Rencana dana nagari yang bersumber dari APBN

2) Rencana Alokasi Dana Desa (ADD) yang merupakan bagian dari dana perimbangan yang diterima Kabupaten/Kota

3) Rencana bagian dari hasil pajak daerah dan retribusi daerah Kabupaten/Kota

4) Rencana bantuan keuangan dari anggaran pendapatan belanja daerah Kabupaten/Kota.

d. Pencermatan Ulang RPJMDes

Tim penyusunan RKP Nagari mencermati skala prioritas usulan rencana kegiatan pembangunan Nagari untuk 1 (satu) tahun anggaran berikutnya sebagaimana tercantum dalam dokumen RPJMDes. Hasil pencermatan sebagaimana dimaksud menjadi dasar bagi tim penyusun RKP Nagari dalam menyusun rancangan RKP Nagari.

e. Penyusunan Rancangan RKP Nagari

Penyusunan rancangan RKP Nagari berpedoman kepada :

1) Hasil kesepakatan musyawarah Nagari

2) Pagu Indikatif Nagari 
3) Pendapatan asli Nagari

4) Rencana kegiatan pemerintah, pemerintah daerah provinsi, dan pemerintah daerah Kabupaten/Kota

5) Jaring aspirasi masyarakat yang dilakukan oleh DPRD Kabupaten/Kota

6) Hasil pencermatan ulang dokumen RPJMDEs

7) Hasil kesepakatan kerjasama antar nagari

8) Hasil kesepakatan kerjasama nagari dengan pihak ketiga.

f. Penyusunan RKP Nagari melalui Musyawarah Rencana Pembangunan Nagari (Musrenbang) Nagari

Wali Nagari menyelenggarakan musyawarah perencanaan pembangunan nagari yang diadakan untuk membahas dan menyepakati rancangan RKP Nagari. Musyawarah perencanaan pembangunan nagari diikuti oleh Pemerintah Nagari, Badan permusyawaratan Nagari, dan unsur masyarakat. Unsur masyarakat terdiri atas tokoh adat, tokoh agama, tokoh masyarakat, tokoh pendidikan, perwakilan kelompok tani, dan lain-lain.

g. Penetapan RKP Nagari

1) Hasil kesepakatan musyawarah perencanaan pembangunan nagari dituangkan dalam berita acara.

2) Wali Nagari mengarahkan tim penyusun RKP Nagari melakukan perbaikan dokumen rancangan RKP Nagari berdasarkan hasil kesepakatan musyawarah perencanaan pembangunan Nagari.

3) Rancangan RKP Nagari menjadi lampiran rancangan peraturan Nagari tentang RKP Nagari.

4) Tim Penyusun RKP membuat rancangan peraturan nagari tentang RKP Nagari yang akan dibahas dan disepakati bersama oleh Wali Nagari dan Badan permusyawaratan Nagari untuk ditetapkan menjadi peraturan Nagari tentang RKP Nagari.

Setelah dilakukan pembahasan terhadap materi bahasan, selanjutnya seluruh peserta Musyawarah Rencana Pembangunan (Musrenbang) dalam rangka penyusunan Rencana Kerja Pemerintah (RKP) Nagari Tabek Panjang Tahun 2018. Memutuskan dan Menyepakati beberapa hal yang bertetapan menjadi Keputusan Akhir dari Musrenbang, yaitu :

1) Penghasilan tetap Wali Nagari dan Perangkat Nagari

a) Penghasilan tetap dan tunjangan.

b) Penunjang Operasional Pemerintahan Nagari.

c) Belanja modal.

d) Penunjang Operasional Bamus Nagari.

e) Penyusunan tata ruang Nagari.

f) Penyelenggaraan Musna.

g) Pengelolaan informasi nagari.

h) Penyelenggaraan perencanaan nagari

i) Penyelenggaraan evaluasi tingkat perkembangan pemerintah nagari.

j) Pembangunan sarana dan prasarana kantor pemerintah nagari.

2) Pelaksanaan penyelenggaraan Pembangunan Nagari

a) Pembangunan dan pemeliharaan jalan pemukiman.

(1) Pemeliharaan jalan Nagari Tabek Panjang.

b) Pembangunan dan pemeliharaan jalan nagari antar pemukiman ke wilayah pertanian.

(1) Pendaman jalan tepi tebing dari rumah Nurlela ke Kantor Pos Ronda Koto Katiak.

c) Pembangunan, Pemeliharaan dan Pengelolaan Irigasi

(1) Lanjutan Pembangunan saluran irigasi Takuak Gadang dan surau rakik Baso.

(2) Lanjutan pembangunan irigasi Baruah - Gobah.

(3) Pembangunan irigasi dari sungai garumbuang - rawang.

(4) Peningkatan saluran irigasi banda surau iliran - Munggu Gadang. 
d) Pembangunan, Pemanfaatan dan Pemeliharaan Posyandu, Polindes, Pos Kesehatan Nagari

(1) Pembangunan posyandu Sungai lamak - Sungai Cubadak.

(2) Pengganti Transportasi kader Posyandu dan PMT.

e) Pembinaan Kesehatan Masyarakat Nagari

(1) Koordinasi kesehatan dalam pelaksanaan kegiatan kesling, toga, dan penyuluhan kesehatan.

(2) Peningkatan koordinasi posyandu dengan Lembaga Kesehatan.

(3) Penyuluhan Narkotika.

(4) Penyuluhan penyakit menular.

(5) Pemberantasan jentik nyamuk.

f) Pembangunan, Pemanfaatan, Pemeliharaan sarana dan prasarana taman bacaan masyarakat

(1) Biaya pengelolaan taman bacaan nagari.

g) Pembangunan, pemanfaatan dan pemeliharaansarana dan prasarana PAUD

(1) Bantuan honor dan tranportasi pendidik Paud (TK).

(2) Pengadaan APE dalam dan APE luar.

(3) Peningkatan kapasitas pendidik Paud.

(4) Pemeliharaan gedung Paud.

h) Pembangunan, pemanfaatan dan pemeliharaan sarana dan prasarana pengembangan dan pembinaan sanggar seni

(1) Pembinaan kelompok randai.

(2) Pembinaan kelompok dikia rebana.

(3) Pengadaan alat kesenian tradisioanl.

(4) Pengadaan pakaian kesenian tradisional.

i) Peningkatan siswa kurang mampu

(1) Pemberian beasiswa bagi siswa kurang mampu.

j) Pembentukan dan pengembangan BUMNag

(1) Pelatihan pengelolaan BUMNag.

(2) Penambahan modal BUMNag.

k) Pembukaan lahan pertanian

(1) Membuat kebun bibit.

(2) Gerakan penanaman seribu pohon.

3) Pembinaan Kemasyarakatan

a) Pembinaan lembaga masyarakat.

b) Penyelenggaraan ketentraman dan ketertiban umum.

c) Pembinaan bidang agama.

d) Pembinaan olahraga.

e) Pembinaan lembaga adat.

f) Pembinaan kesenian dan sosial budaya.

g) Peringatan hari besar nasional.

4) Pemberdayaan Masyarakat

a) Pelatihan usaha ekonomi, pertanian, perikanan, dan perdagangan.

b) Pendidikan, pelatihan dan penyuluhan bagi Walinagari, Perangkat Nagari dan Bamus Nagari.

c) Peningkatan kapasitas kelompok perempuan.

d) Peningkatan kapasitas kelompok Tani.

e) Pemberdayaan kesejahteraan keluarga.

\section{Anggaran Pendapatan dan Belanja Nagari (APBNag)}

Anggaran Pendapatan dan Belanja Nagari (APBNag) adalah instrumen penting yang sangat menentukan dalam rangka perwujudan tata pemerintahan yang baik dan pelaksanaan pembangunan di tingkat nagari. Tata pemerintahan yang baik, diantaranya diukur dari proses penyusunan dan pertanggungjawaban APBNag. Memahami proses 
pada seluruh tahapan pengelolaan APBNag (penyusunan, pelaksanaan, pertanggungjawaban) memberikan arti terhadap model penyelenggaraan pemerintah nagari itu sendiri. Berikut dapat kita lihat Flowchart prosedur penerimaan Alokasi Dana Desa (ADD) Tahun Anggaran 2018 pada Nagari Tabek Panjang

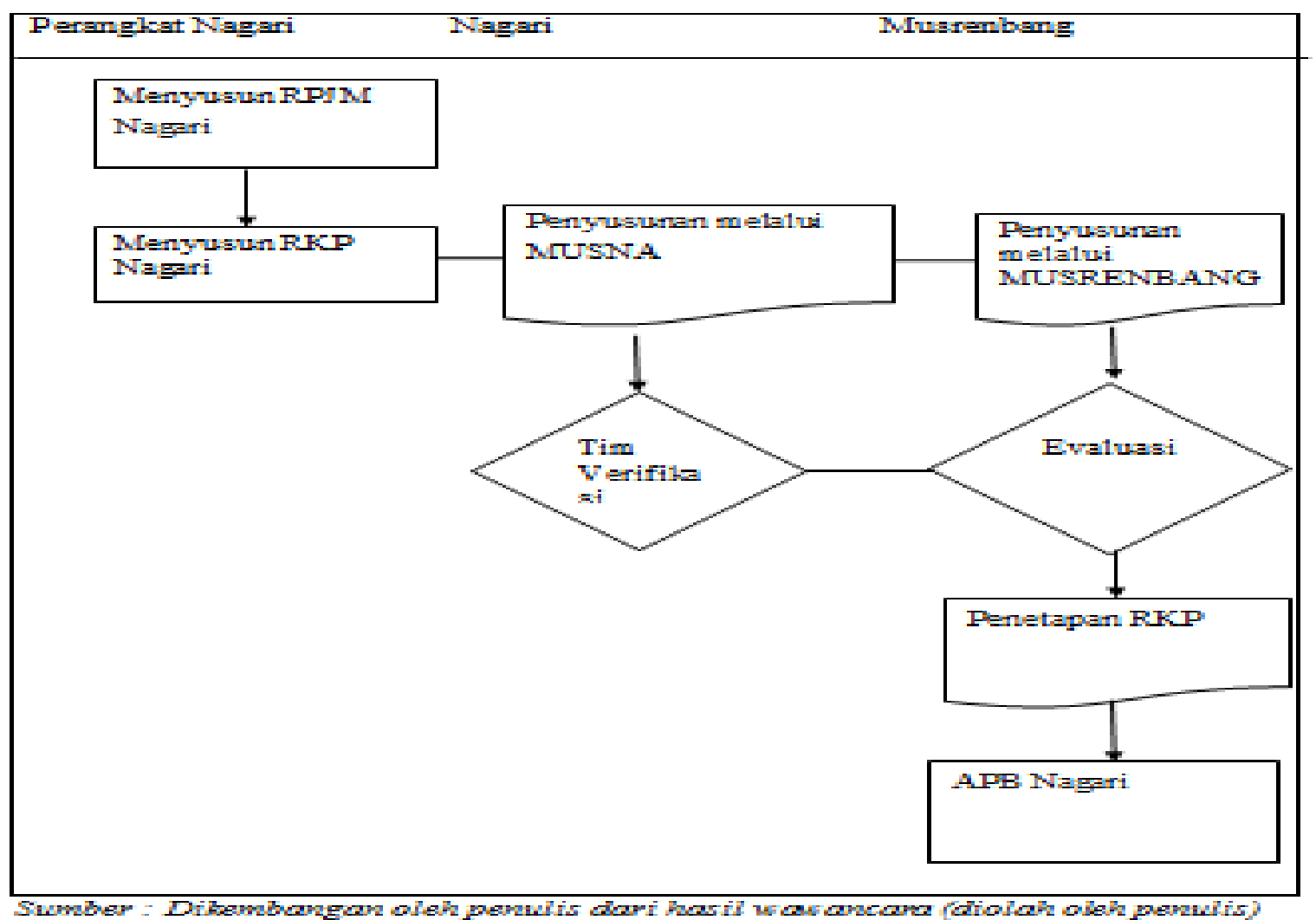

Gambar 2. Flowchart Prosedur Penerimaan ADD

\section{Analisis Pencairan dan Penerimaan Alokasi Dana Desa (ADD)}

Analisis proses pencairan dan penerimaan alokasi dana desa (ADD) , Berdasarkan hasil penelitian ADD merupakan salah satu sumber pendapatan Nagari yang bersumber kepada APBD Daerah tingkat kabupaten Agam. Dari informasi yang diperoleh proses pencairan ADD di Nagari Tabek Panjang terbagi atas 2 (dua) tahap, yaitu :

1. Penghasilan tetap Wali Nagari dan perangkat Nagari serta tunjangan Bamus yang terbagi atas 4 (empat) triwulan yang masing-masingnya sebesar $25 \%$.

2. Pencairan Alokasi Dana Desa (ADD) selain dari penghasilan tetap perangkat Nagari serta tunjangan Bamus yang dilakukan secara bertahap yaitu tahap I, II, III yang dilengkapi dengan surat rekomendasi dari Camat untuk pengajuan pencairan dana, dan untuk pengajuan tahap II dan III harus melaporkan pertanggungjawaban kepada Dinas Pemerdayaan Masyarakat Nagari (DPMN) Kabupaten Agam.

Adapun tahap - tahap dalam Prosedur Penerimaan Alokasi Dana Desa (ADD) pada Nagari Tabek Panjang, yaitu :

1. Penyusunan Rencana Pembangunan Jangka Menengah (RPJM) Nagari yang diatur dalam persetujuan Bupati No. 542017 tentang petunjuk teknis Penyusunan Rencana Pembangunan Jangka Menengah (RPJM) Nagari.

2. Penyusunan Rencana Kerja Pemerintah (RKP) Nagari Tabek Panjang 2018, sesuai peraturan Menteri Dalam Negeri (Permendagri) Nomor 114 Tahun 2014 tentang pedoman pembangunan Nagari.

3. Menyusun Anggaran Pendapatan dan Belanja Nagari (APBNAg) Tabek Panjang 2018

Memahami proses dari seluruh tahapan Prosedur Pencairan dan Penerimaan Alokasi

Dana Desa (ADD) Nagari Tabek Panjang 2018 memberikan arti terhadap model 
penyelenggaraan pemerintah Nagari itu sendiri agar terlaksana sesuai yang telah direncanakan dan diharapkan agar tercipta kesejahteraan masyarakat Nagari.

\section{KESIMPULAN DAN SARAN}

Berdasarkan pembahasan hasil penelitian yang telah dibahas pada bab sebelumnya, maka dapat disimpulkan sebagai berikut:

1. Prosedur Pencairan Alokasi Dana Desa (ADD) Nagari Tabek Panjang 2018 dilakukan melalui 3 (tiga) tahap yaitu tahap I sebasar 40\%, tahap II sebesar 40\%, dan tahap III sebesar $20 \%$.

2. Proses Penerimaan Alokasi Dana Desa (ADD) Nagari Tabek Panjang 2018 sudah sesuai dengan peraturan Pemerintah yaitu Penyusunan Rencana Pembangunan Jangka Menengah (RPJM) Nagari yang diatur dalam persetujuan Bupati No. 542017 tentang petunjuk teknis RPJM Nagari Tabek Panjang, Penyusunan Rencana Kerja Pemerintah (RKP) Nagari sesuai dengan peraturan Menteri Dalam Negeri (Permendagri) Nomor 114 Tahun 2014 tentang pedoman pembangunan Nagari, Menyusun Anggaran Pendapatan dan Belanja Nagari (APBNag) Tabek Panjang 2018.

Berdasarkan kesimpulan di atas, maka dapat disarankan sebagai berikut:

1. Dalam Prosedur Pencairan Alokasi Dana Desa (ADD) Pemerintah Nagari harus sesuai dengan Peraturan - peraturan Bupati dan sesuai dengan prosedur yang telah ditetapkan.

2. Dalam proses Penerimaan Alokasi Dana Desa (ADD) Pemerintah Nagari harus sesuai dengan prosedur yang telah ditentukan dan mengutamakan sifat kehati - hatian agar tidak terjadi kesalahan dan tercapainya tujuan yang telah direncanakan

3. Pemerintah mengedepankan keterbukaan dalam hal pertanggungjawaban anggaran ADD kepada masyarakat Nagari, karena masyarakat mempunyai hak untuk mengetahui penggunaan ADD tersebut.

\section{DAFTAR KEPUSTAKAAN}

Puspitawat, Lilis, Sri Dewi Anggadini. 2010. Sistem Informasi Akuntansi. Yogyakarta: Graha Ilmu.

Mulyadi. 2011. Akuntansi Sector Publik. Yogyakarta: Salemba Empat

Mulyadi. 2011. Sistem Akuntansi. Yogyakarta: Salemba Empat

Nuraida, Ida. 2014. Manajemen Administrasi Perkantoran Edisi Revisi, Yogyakarta; PT Kanisius.

Mulyadi. 2013. Sistem Akuntansi. Jakarta: Salemba Empat.

Rasto, 2015. Manajemen Perkantoran Paradigma Baru. Bandung: Alfabeta.

Romney, Marshall B, dan Steinbart, 2015. Sistem Informasi Akuntansi. Edisi 13 , Alihbahasa: Kikin Sakinah Nur Safira dan Novita Purpasari, Jakarta: Salemba Empat

Anastasia Diana, Lilis Setiawati. 2011. Sistem Informasi Akuntansi, Perancangan, Prosedur dan Penerapan. Edisi 1. Yogyakarta: Andi Yogyakarta

Mulyadi, 2016. Sistem Informasi Akuntansi. Jakarta: Salemba Empat.

Weygandt, Jerry J, Donald E. Kieso, \& Paul D. Kimmel. 2011. Pengantar Akuntansi. Edisi 7, Buku 2. Jakarta: Salemba Empat.

Howard F. Stettler, 2010. Auditing Principles Objectives, Prosedures, Working Paper. Dikutip oleh Zaki Baridwan, Jakarta: Salemba Empat.

Baridwan, Zaki. 2010. Sistem Akuntansi: Penyusunan Prosedur dan Motode. Edisi kelima, Badan Penerbitan Fakultas Ekonomi, Yogyakarta.

KBBI. 2019. Kamus Besar Bahasa Indonesia (KKBI). (Online) Available at: http:// text id.123dok.com/document /myjdo55my - pencairan - dana. Diakses 29 Agustus 2019

Deddi Nordiawan. 2010. Akuntansi Sektor Puplik. Jakarta: Salemba Empat. 
Soematri. 2011. Pemerintah Desa. Jakarta: Erlangga.

Suharto, Edi. 2010. Membangun Masyarakat Memberdayakan Rakyat, Bandung: Refika Aditama.

Abdul Halim \& Syam Kusufi. 2012. Akuntansi Sektor Publik: Teori, Konsep dan Aplikasi. Jakarta: Salemba Empat.

Chabib Sholeh dan Heru Rochmansjah. 2010. Pengelolaan Keuangan dan Aset Daerah Sebuah Pendekatan Struktural Menuju Tata Kelola Pemerintahan yang Baik. Bandung: Fokusmedia.

Indrajani. 2015. Database Design (Case Study All in One). Jakarta: PT Elex Media Komputindo

Nurcholis. 2011. Pendapatan Desa. Jakarta: Erlangga.

Repuplik Indonesia. 2005. Peraturan Pemerintah No 58 Tahun 2005 tentang Pengelolaan Keuangan Daerah, Jakarta: Legalitas.

Peraturan Menteri Dalam Negeri Nomor 13 Tahun 2006 Tentang Pedoman Pengelolaan Keuangan Daerah.

Peraturan Menteri Dalam Negeri Repuplik Indonesia Nomor 113 Tahun 2014. Tentang Pedoman Pengelolaan Keuangan Desa.

Peraturan Pemerintah Nomor 72 Tahun 2005 Tentang Desa.

Peraturan Menteri Dalam Negeri Nomor 37 Tahun 2007 Tentang Pedoman Pengelolaan Keuangan Desa.

Undang - Undang Nomor 6 Tahun 2014 Tentang Desa, Lembaran Negara Repuplik Indonesia Tahun 2014 Nomor 7, Tambahan Lembaran Negara Nomor 5495.

Undang - Undang Dasar Negara Repuplik Indonesia Tahun 1945.

Undang - Undang Repuplik Indonesia Nomor 32 Tahun 2004 tentang Pemerintahan Daerah.

Undang - Undang Nomor 6 Tahun 2014 tentang Desa BAB VIII Keuangan Desa dan Aset Desa.

Peraturan Pemerintah Repuplik Indonesia Nomor 72 Tahun 2005. Tentang Desa.

Peraturan Pemerintah Repuplik Indonesia Nomor 60 Tahun 2014. Tentang Dana Desa.

Undang - Undang Nomor 17 Tahun 2003 Tentang Keuangan Negara. 